\title{
Effect Of Poisson's Ratio Of Core Clay On Dynamic Settlement Of The Earth Dams
}

\author{
${ }^{1}$ Behrouz Gordan, ${ }^{2}$ Azlan Bin Adnan \\ ${ }^{1 .}$ Faculty of civil Engineering, University Teknologi Malaysia 81310 Skudai, Johor, Malaysia \\ ${ }^{2}$. Head of Earthquake Department University Teknologi Malaysia81310Skudai,Johor, Malaysia
}

\begin{abstract}
Construction earth dam is developed to access supply resources. This paper tried to evaluate numerical analysis of the dynamic settlement during the earthquake in different conditions of the Poisson's ratio from core clay. Models were carried out with NAGAN record. ANSYS software is used regard to Finite-element method. Literature indicated that the maximum displacement during the earthquake is conducted at the crest. Interaction between dam and foundation is cased it. Lateral strain is administered the zero so models were considered in plan strain method. This paper considered end of construction with fill up reservoir when the core clay is saturated. Effect of Poisson's ratio on maximum settlement is evaluated. It was regarded the range between 0.2-0.45 for saturate and un saturate respectively. Results indicated that increase of the Poisson's ratio for saturate condition was caused to reduction of the maximum settlement at the crest and middle of core. It is mentioned the end of construction was at the critical state.
\end{abstract}

Keywords: Dynamic settlement, Poisson's ratio, Clay core, ANSYS software.

\section{Introduction}

Due to design of the earth dam regard an increase of construction, control dynamic settlement is required because there are good samples was damaged during the earthquake. Therefore, it is concerned to evaluate and best researches about influence of the dynamic load settlement in the earth dam during an earthquake. Literature review indicated that since the beginning of 1920s and up to 1960s 'Pseudo-static method' of analysis was well-known. However, this method was very simple, and it could not account on the nature of the slope-forming material or the foundation material. Based on deformation characteristics, NEWMARK [8] was proposed 'Sliding block method'. Among other methods, 'Shear beam model' analysis was quite popular. This method was introduced by MONONOBE [7]. GAZETAS [3] proposed an improved 'Inhomogeneous shear beam model' which can take care of the fact that the shear modulus in earth or rock-fill dams is not constant but increases with 2/3 power of depth from the crest. CLOUGH and CHOPRA [2] were introduced the finite-element method for two-dimensional plane-strain analysis to estimate the dynamic response of an embankment assuming that it consists of linearly elastic, homogeneous, isotropic materials. Later, several other researchers developed the finite element and finite difference method for non-linear, inelastic, non homogeneous, anisotropic behavior of materials under seismic conditions. ZEGHAL and ABDELGHAFFAR [13] were proposed a local-global finite element method of analysis for determination of the nonlinear seismic behavior of earth dams. Ming and Li [6] conducted a fully coupled finite-element analysis of failure of Lower San Fernando dam and examined the possible reason of the dam failure. Quick development of computer programs had a useful information of earthquake engineering research. For example, several computer programs like [4, 5, 9and12] were used worldwide for the intensive seismic analysis of the earthen dam. SEIDKARBASI and BYRNE [11] and PIAO et al[10] were represented the dynamic analysis of the earth dams using the finite difference method based computer code FLAC. ZHU et al [1] have presented a two-dimensional analysis of embankment using finite element based program PLAXIS. Shortly, the maximum displacement during the earthquake is induced at the crest. Interaction between dam, and foundation is caused it. This paper considered the effect of Poisson's ratio on maximum settlement at the end of construction regard to two conditions. The first is represented the un saturated dam and second is conducted to saturated dam when it is coupled the reservoir. Briefly, this paper was evaluated the effect of Poission's ratio in clay core on dynamic settlement of the earth dam.

\section{II. process of model}

This is included some step such as element selection, Boundary conditions, Parametric dimension, Material properties, Meshing and earthquake record. Modeling process is described step by step below. 


\section{2-1 Introduce ANSYS Software}

This software is comprehensive regarded the finite-element method and has the 100000 code line. It is related the computer-aided engineering (CAE) and very important, specifically. In fact, it is famous on most of the finite-element software individually.

\section{2-2Element selection}

In this research solid42 is selected for material element in all parts of structure such as shell, core and foundation. In add, fluid79 is used for water element according to recommended by ANSYS help. Both elements regarded the plane strain conditions because the lateral strain is concerned the zero. It was corresponded the literature.

\section{2-3Boundary conditions}

Nagan earthquake is used with acceleration-time for modeling. It was converted the displacement-time by another software regarded the SISMOSOFT 3. Later, add horizontal displacement shown 0.43 meter at the end of earth quake. Even so, it was a good estimate that 0.2 meter for cumulative vertical displacement. Thus, vertical displacement in horizontal boundaries was zero and horizontal displacement is applied the NAGAN record. Horizontal boundary is represented a bottom of the foundation as mentioned the bedrock. However, there were two vertical lines at the boundary. Vertical displacement is applied regarded the 0.2 meter for both. In add, Horizontal displacement is induced them with 0.01 meter. It was administered the elasticity property of waves in the model.

\section{2- 4Parametric modeling and dimensions}

Table 1 shown the parametric model and introduced the different parts of models. It is included some parts such as shell, core, water and foundation with two conditions. They were placed under of structure and tank. Moreover, solid materials as mentioned were placed in two conditions regard to saturate and un saturate states. In add, Figure 1 is described the model dimension. All parameters were depended upon the dam height.

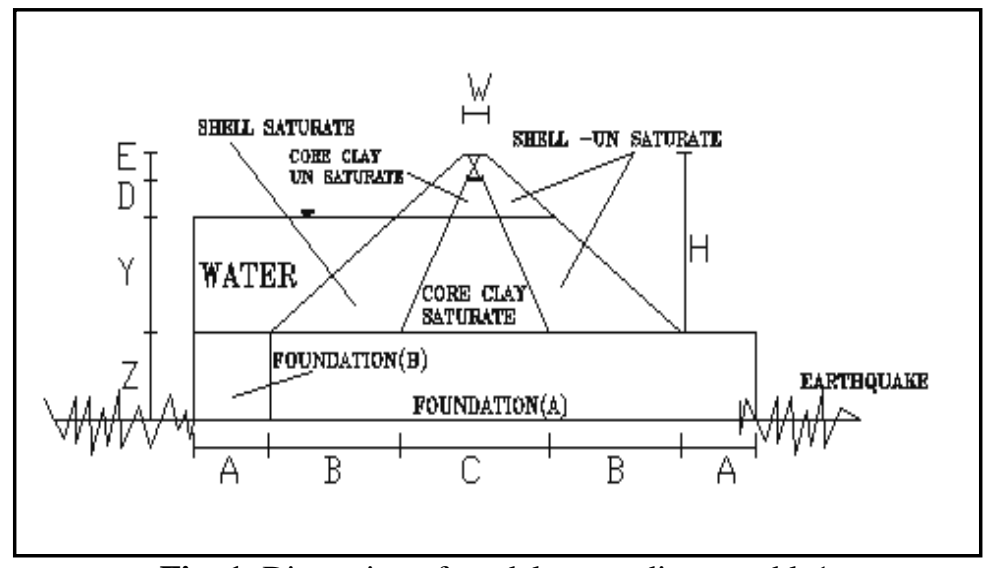

Fig. 1: Dimention of models according to table1

Table 1: Dimension value of model.

\begin{tabular}{lllll}
\hline $\mathrm{H}=30 \mathrm{~m}$ & $\mathrm{~A}=0.5 \mathrm{H}$ & $\mathrm{B}=0.865 \mathrm{H}$ & $\mathrm{C}=0.985 \mathrm{H}$ & $\mathrm{D}=0.15 \mathrm{H}$ \\
& & & & \\
$\mathrm{E}=0.15 \mathrm{H}$ & $\mathrm{W}=0.33 \mathrm{H}$ & $\mathrm{X}=0.1 \mathrm{H}$ & $\mathrm{Y}=0.7 \mathrm{H}$ & $\mathrm{Z}=0.2 \mathrm{H}$ \\
\hline
\end{tabular}

\section{2-5Material Properties}

In this part, four material properties were introduced. They were included the water, foundations, core and shell. Moreover, ANSYS LIQUID suggested the Non-compressible properties from the tank. All as mentioned were corresponded to the Table 1 .

Table2: Material Properties.

\begin{tabular}{|l|l|l|l|l|l|}
\hline Zone & $\begin{array}{l}\text { Elasicity } \\
\text { Modulus } \\
\left(\mathrm{Kg} / \mathrm{m}^{2}\right)\end{array}$ & $\begin{array}{l}\text { Relative } \\
\text { Density } \\
\left(\mathrm{Kg} / \mathrm{m}^{3}\right)\end{array}$ & $\begin{array}{l}\text { Yield stress } \\
\left(\mathrm{Kg} / \mathrm{m}^{2}\right)\end{array}$ & $\begin{array}{l}\text { Tangent } \\
\text { Modulus } \\
\text { coefficient }\end{array}$ & $\begin{array}{l}\text { Poisson } \\
\text { Ratio }\end{array}$ \\
\hline Shell & $1.00 \mathrm{E} 8$ & 1900 & $7 \mathrm{E} 6$ & 0.01 & 0.25 \\
\hline Core & $3.50 \mathrm{E} 7$ & 1850 & $1.05 \mathrm{E} 6$ & 0.01 & $0.2 \& 0.45$ \\
\hline Foundation & $2.00 \mathrm{E} 7$ & 1800 & $1.05 \mathrm{E} 6$ & 0.01 & 0.20 \\
\hline Water & $1.00 \mathrm{E} 10$ & 1000 & ------- & ------- & 0.001 \\
\hline
\end{tabular}




\section{2-6Main points and Meshing}

There were some main points in models as illustrated in Fig. 2. They were introduced critical view points to extract exist data. Points 1-2 were placed on the crest. In add, points 9-10 were placed in the middle of core clay and foundation respectively. Other points were located on the interface line between different parts for models.

Moreover, Figure3 illustrated the plan mesh with a regular method regard the best effect of interaction. It is carried out with node to node meshing in models.

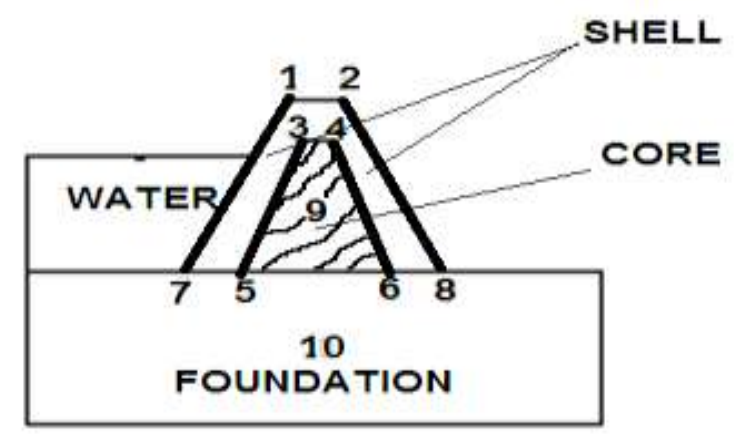

Fig.2: This Figure is explained the main points to gather the exist data.

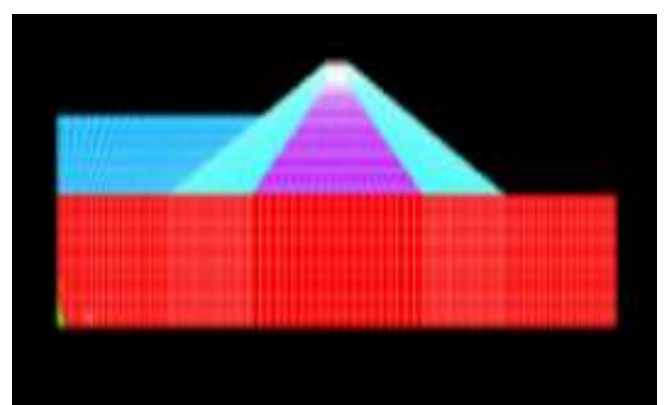

Fig. 3: This figure illustrated the mesh model with the regular methods.

\section{2-7 Earthquake record}

Both models were evaluated by NAGAN record. This record had an acceleration-time with PGA $=0.65 \mathrm{~g}$ and 5.02 second for time. Moreover, record is converted to displacement-time for input data in ANSYS by SISMOSOFT3 software. Figure 4 illustrated the NAGAN record with time acceleration to time displacement was converted. Figure 5 indicated that maximum and minimum displacement was $16.5 \mathrm{~mm}$ and $11 \mathrm{~mm}$ respectively. All the sub steps were 0.02 and record was covered 5.02 second, and PGA $=0.65 \mathrm{~g}$. PGA was introduced the peak at ground acceleration.

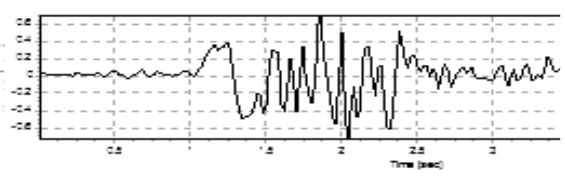

A) Time-acceleration

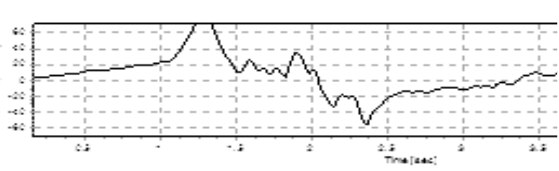

B) Time-velocity

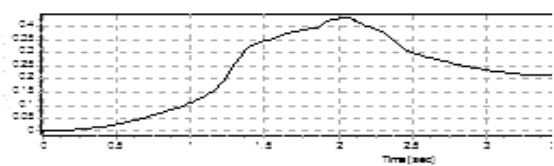

C) Comulative Time- displacement

Fig. 4: Convert acceleration-time to displacement-time by Sismosoft 3 and in the (a-c)conditions, horizontal direction is the time(second) and vertical axis are acceleration $(\mathrm{g})$, velocity $(\mathrm{m} / \mathrm{s})$ and comulative displacement $(\mathrm{cm})$ respectively. 


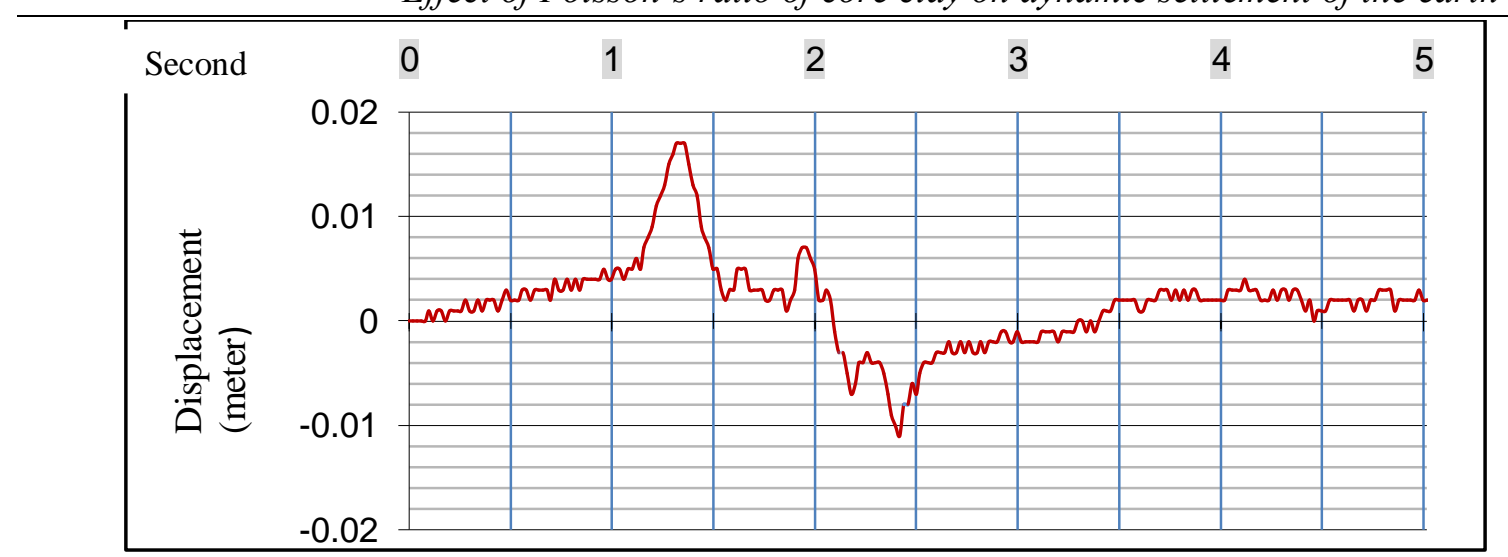

Fig. 5: It has shown the input data of NAGAN earthquake record. Vertical and horizontal axis is concerned the displacement(m) and time (second) respectively.

\section{2-8 Chart of numerical modeling}

This chart is introduced a process of numerical modeling, and Figure6 illustrated it. It is included five steps such as input data, Dynamic analysis, Exist data, Results Analysis and conclusion.

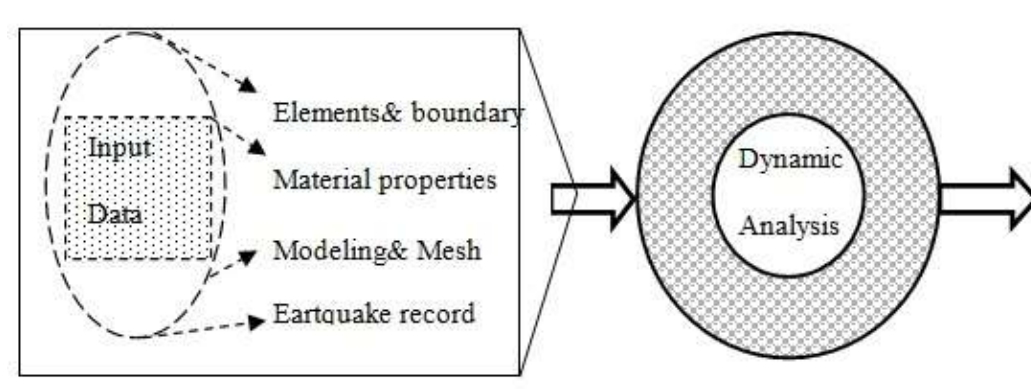

Fig. 6: Process of numerical analysis.

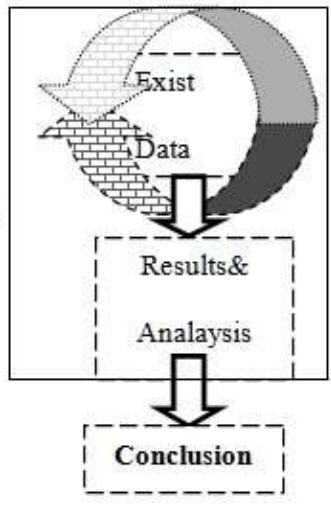

\section{Results Analaysis}

Time history of models is carried out. Focus to main points as mentioned was caused to some analyses. Figure 7 is represented the mesh model after the end of earthquake. It was exaggerated and indicated the settlements dynamic during the earthquake is occurred. Moreover, Figure 8 demonstrated the non linear behavior. It is shown the value of vertical displacements were changed when the sub steps were increased. It was same for all main points.

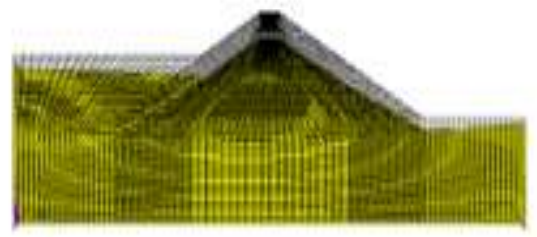

Fig. 7: shown all of the nodes after earthquake on every sub step.(white color is normal earth dam and yellow color is after earthquake).

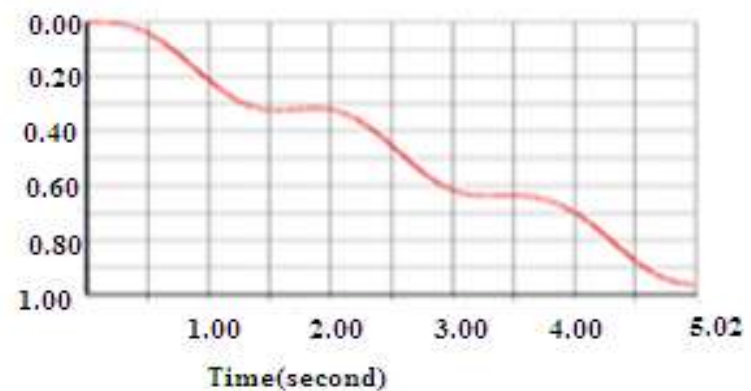

Fig. 8: It is shown thevertical displacement-time during the earthquake in point 1.Vertical axis is displayed the vertival displacemet (meter) and Horizontal axis is represented the time(second). 
Furthermore, all nodes were found at the same regular process. In addition, this function was introduced one of the strong abilities from ANSYS 13. So far, dimensional of dynamic settlement is covered meter from Unit of Measure. After analysis of models with both Poission's ratio for different situation of solid materials in core clay individually so results were classified. Table 3 illustrated the value of vertical displacement at the end of earthquake. Unit of Measurement was covered by meter. It is mantioned the model 1 is introduced the core clay at the end of construction with un saturated situation. Model 2 is represented the saturat core clay. It was conducted the interaction between reservior and structure when the seepage phase is accoured. Both models were corresponded the poisson ratio between 0.2-0.45 respectively.

Table 3: value of dynamic settlement numerical analysis by meter dimension

\begin{tabular}{|l|l|l|l|l|l|l|l|l|l|l|}
\hline Type / Main points & 1 & 2 & 3 & 4 & 5 & 6 & 7 & 8 & 9 & 10 \\
\hline $\mathrm{v}=0.2$ - Model 1 & 0.984 & 1.00 & 1.01 & 1.00 & 0.82 & 0.7 & 0.68 & 0.50 & 0.983 & 0.54 \\
\hline $\mathrm{v}=0.45$-Model 2 & 0.443 & 0.44 & .445 & 0.443 & 0.25 & 0.20 & 0.16 & 0.05 & 0.417 & 0.18 \\
\hline
\end{tabular}

Figure 9 is corresponded to results from Table 3. It was revealed the vertical displacement was covered at the minimum value in toe point. It was placed at the point 8 . It was far from of the hydrodynamic pressure during the earthquake. Moreover, Maximum displacement was occurred at the crest. It was corresponded to literature and so capability to crack's generation at the crest. Interaction between reservoir and dam during dynamic load was caused it. Furthermore, this value was grater in the middle of core clay rather than center point of foundation.

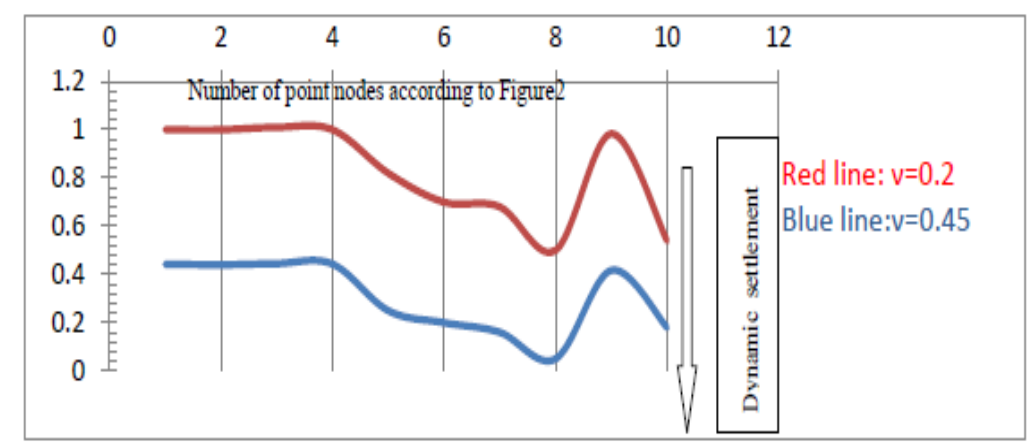

Fig. 9: It has shown dynamic vertical displacement at the end of earthquake for both of Poisson's ratio in the core clay of the earth dam with $30 \mathrm{~m}$ of height for main points. Vertical axis is represented the dynamic displacement(meter).

However, the vertical dynamic displacement in all main points was reduced when the Poisson's ratio is increased regard to saturate situation from core clay. It was revealed that the critical state was conducted the end of construction before then fill up tank because the vertical displacement was located at the maximum value. Shortly, analysis of results demonstrated the increase of the Poisson's ratio in saturate condition was caused to reduction of the maximum displacement at the crest and middle of core clearly.

\section{Akcnowledgment}

This study is made possible by the support of the International Doctorate Fellowship of Universiti Teknologi Malaysia, and it is very much appreciated.

\section{V. conclusion}

Value of the dynamic displacement from the middle of core was more than center point of foundation. Minimum vertical displacement is related to toeing of the earth dam. It was found the increase of Poisson's ratio caused to reduce of active settlement. Dynamic displacement after fill up the reservoir was less than the end of construction. It is mentioned the end of construction was at the critical state. Finally, both models were focused a common problem at the crest. Thus, attention to improvement ways to reduce dynamic settlement is important for future.

\section{References}

[1]. Zhu, Y., K. Lee and G.H. Collison, (2005). A 2D seismic stability and deformation analysis. Proceeding of the Geo-Frontiers, Jan. 24-26, ASCE., Austin, Texas, pp: 1-5.http://www.golder.com/archive/2005Geo_PTFI.pdf

[2]. Clough, R.W. and A.K. Chopra, (1966). Earthquake stress analysis in earth dams. J. Eng. Mech., ASCE., 92: 197-211. http://nisee.berkeley.edu/elibrary/Text/300451

[3]. Gazetas, G., (1981). A new dynamic model for earth dams evaluated through case histories. Soils Foundat.,21: 67-78. http://ci.nii.ac.jp/naid/110003914595 
[4]. Hudson, M., I.M. Idriss and M. Beikae, (1994). User's manual for QUAD4M. Center for Geotechnical Modeling, Department of CivilandEnvironmentalEngineering,UniversityofCalifornia,Davis,CA.,USA.http://cgm.engineering.ucdavis.edu/Publications/reports /Quad4M_manual_rev2003.pdf

[5]. ITASCA, (2000). Fast lagrangian analysis of continua. Version 4, User's Guide, ITASCAConsulting Group, Minneapolis, Minnesota, USA. http://www.aimil.com/flac3d.aspx

[6]. Ming, H.Y. and X.S. Li, (2003). Fully coupled analysis of failure and remediation of lower San Fernando dam. J. Geotechnic. Eng. Div., ASCE., 129: 336-349. DOI: 10.1061/(ASCE) 1090-0241(2003)129: 4(336)

[7]. Mononobe, H.A., (1936). Seismic stability of the earth dam. Proceeding of the 2nd Congress on Large Dams, (CLD’36), Washington DC., USA., pp: 435-442.

[8]. Newmark, N.M., (1965). Effects of earthquakes on dams and embankments. Geotechnique, 15: 139-160. http://www.civil.ubc.ca/liquefaction/Publications/H yropower\&Dams.pdf

[9]. Ordóñez, G.A., (2000). SHAKE2000: A computer program for the 1D analysis of geotechnical earthquake engineering problems. http://www.shake2000.com/index.htm

[10]. Piao, R., A.H. Rippe, B. Myers and K.W. Lane,(2006). Earth dam liquefaction and deformation analysis using numerical modeling. Proceeding of the Geo Congress (GC'06), ASCE., pp: 1-6. DOI: 10.1061/40803(187)217 Am. J. Engg. \& Applied Sci., 2 (3): 559564,2009

[11]. Seid-Karbasi, M. and P. Byrne, (2004). Embankment dams and earthquakes. Hydropower Dams, 2: 96-102. http://www.civil.ubc.ca/liquefaction/Publications/H yropower\&Dams.pdf

[12]. TAGA soft Limited, (1998). TELDYN-Users' manual. Lafayette, California. http://www.tagasoft.com

[13]. Zeghal, M. and A.M Abdel-Ghafar, (1992). Local global finite element analysis of the response of earth dams. Computer Structure.,42:569-579.DOI:10.1016/0045-7949(92)90124-I 